\title{
Application of satellite images for assessing winter wheat and spring barley crops on the average NDVI value
}

\author{
Ninel Pavlovskaya *, Sergei Rodimtsev, Dmitrii Borodin, Stepan Vershinin, \\ Irina Gagarina *, Yulia Mikhaylova \\ Orel state agrarian university named after N.V. Parakhin 69, General Rodin Str., Orel, Russia
}

\begin{abstract}
The article presents data on the state of the surveyed fields of winter wheat and spring barley of the experimental farm "Integration" of the Orel state agrarian university using satellite images. The dynamic values of the Normalized Difference Vegetation Index (NDVI) were obtained by analyzing satellite images of the experimental plots, starting with early flowering phase of agricultural crops. The corresponding maps were prepared based on these data; the data visualization and access to them were implemented on the GeoMixer base of the WebGIS platform. Digital processing of the information was provided with the digital processing program of the Earth remote sensing ScanEx Image Processor V.5.0. The boundaries of the experimental plots were determined by vector pathes (polygons) built into the digital environment of the composite control system (CCS) of the agricultural organization "AgroNetwork Technologies" (ANT). This software is the basis of the digital platform for the experimental farm of the university. The NDVI values for spring barley in the control zone are very low and amount to about 0.5 in the middle of the season, which predicts the yield to be twice lower than the optimal one.
\end{abstract}

\section{Introduction}

In the modern conditions of digital streams intensification in the field of technological processes management of the agro-industrial complex, it is necessary to obtain on-line information on the state of farmlands with an increasing refresh rate. In this situation, it is not enough to use UAVs or least of all traditional methods for obtaining data on the state of the plots. One of the ways to solve these problems is to use satellite data of the Earth remote sensing (ERS), combined with the results of the aerial mapping, which makes it possible to provide the necessary frequency and to use archived data for deeper analysis and prediction of the processes.

Crop management, associated with crop yield prediction, environmental impacts, soil chemical composition, moisture, etc., can be based on the spectral signature of crops, i.e. reflectivity / emissivity depending on the wavelength. Various vegetation indices helping to carry out a qualitative analysis of the state of the vegetation based on the remote sensing are widely used in the world practice of agriculture [1].

\footnotetext{
*Corresponding author: i-gagarina@list.ru
} 
Vegetation indices are an important characteristics for the study of the state of crops, indicating structural, biochemical and physiological changes. Most of the structurally bound plant indices are created based on the analysis of the ratio of the reflected solar radiation intensity in various spectral channels, mainly in the red and near infrared spectrum. The structural properties include: green leaf biomass, leaf area index and photosynthetically absorbed active radiation. The biochemical properties include: coloring agents (chlorophyll, anthocyanin and carotenoids), as well as water, nitrogen compounds, lignin, cellulose, etc. The third category of the state of the vegetation cover includes the physiological state of plants associated with the changes occurring under the influence of various kinds of stress. For example, the changes in the chlorophyll or xanthophyll content, humidity, etc. [2, 3].

The vegetation indices are used to analyze the state of crops, soil nutrient content, nitrogen supply to plants, yield forecast, modeling, etc. $[4,5]$.

Vegetation indices provide with the important information, especially when identifying stress caused by the biogenic or anthropogenic factors for taking well-timed measures; more than that, they are also important for planning and adjusting of the nitrogen nutrition. In Russia, the use of remote sensing data for yield forecast and crop management is not yet widely implemented.

The purpose of our research is to study the possibility of the combined use of the aerial mapping and satellite images of the vegetation cover data in the conditions of the Orel region.

The objectives of the research were:

- to establish the relationship between the crop productivity of winter wheat and spring barley and their NDVI;

- to identify the possibility of using remote sensing data obtained with an aircraft, and the results of the satellite imagery to assess winter wheat and spring barley productivity under the influence of a new biological product.

\section{Material and methods}

The work was carried out in the conditions of the Research and Educational Production Center (REPC) "Integration" of the Federal State Budgetary Educational Establishment of Higher Education "Orel state agrarian university" (FSBEE HE Orel SAU). The area of the experimental plot was 10 hectares per 1 crop. The effect of a new biological product under the operating name "Nigor" [6] with a protective and stimulating property on the productivity of winter wheat "Moskovskaya 40" and spring barley "Scarlet" was studied. The agrochemical characteristics of the soil was: $\mathrm{P}_{2} \mathrm{O}_{5}$ [7] $99 \mathrm{mg} / \mathrm{kg}, \mathrm{K}_{2} \mathrm{O}$ [6] $102 \mathrm{mg} / \mathrm{kg}$, pH 5 [8]; humus according to Tyurin's method modified by the Central Scientific Research Institute of Agrochemical Services for Agriculture (CSRIASA) [9] 4.54. Barley was the predecessor. The soil was gray forest and medium loamy.

The presowing treatment of spring barley "Scarlet" was carried out by mixing the systemic insecticide protectant "Imidor Pro" $0.751 / \mathrm{t}$ and "Biostim Start" $11 / \mathrm{t}$ in the protectant $\mathrm{KC}-10$ and double spraying, using a sprayer AMAZONEN D492-05, in the tillering stage (27.05.2020) along with herbicide "Fenisan", BP $0.151 /$ ha (the operating fluid consumption during the ground treatment was $2001 /$ ha) and in the booting stage (06/15/2020) along with fungicide "Title Duo" 0.251 / ha (the operating fluid consumption during the ground treatment was $2001 /$ ha). The barley was harvested on September 1, 2020 .

Winter wheat "Moskovskaya 40", was double sprayed using sprayer AMAZONEN D492-05 in the tillering stage (05.24.2020) along with the herbicide "Fenizan", BP $0.151 /$ ha (the operating fluid consumption during the ground treatment was $2001 /$ ha) and in the 
booting stage (10.06.2020) along with the fungicide "Title Duo" $0.251 /$ ha (the operating fluid consumption during the ground treatment was $2001 /$ ha).

The agrochemical characteristics of the soil under the winter wheat was: $\mathrm{P}_{2} \mathrm{O}_{5}$ [7] $104 \mathrm{mg} / \mathrm{kg}, \mathrm{K}_{2} \mathrm{O}$ [8] $135 \mathrm{mg} / \mathrm{kg}$, pH 5,5 (GOST 26483-85); humus according to Tyurin's method modified by the CSRIASA [9] 4.09. Soybean was the predecessor. The soil was gray forest and medium loamy. The winter wheat was harvested on August 23, 2020.

During the growing season of the crops phenological observations were carried out, and at the end of the growing season the wheat and barley yield was calculated.

The dynamic values of the vegetation index NDVI were obtained by analyzing satellite images of the experimental plots, starting with early flowering phase of the agricultural crops. The corresponding maps were prepared based on these data; the data visualization and access to them were implemented on the GeoMixer base of the WebGIS platform. Digital processing of the information was provided with the digital processing program of the Earth remote sensing ScanEx Image Processor V.5.0. The boundaries of the experimental plots were determined by vector pathes (polygons) (Fig. 1) built into the digital environment of the composite control system (CCS) of the agricultural organization "Agro-Network Technologies" (ANT). This software is the basis of the digital platform for the experimental farm of the university.

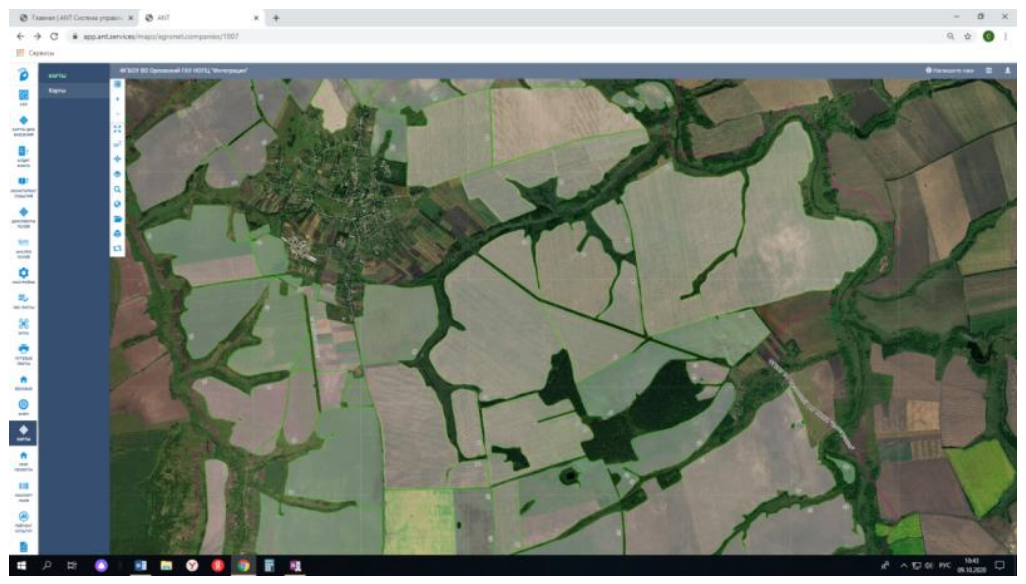

Fig. 1. Screenshot of the tab "Fields" of the CCS of the ANT of the REPC "Integration" (FSBEE HE Orel SAU).

\section{Results and discussion}

As a result of the surveys on June 17, 2020 of the fields with the winter wheat using the satellite images processing in the program ScanEx, the data, indicating the heterogeneity of the state of wheat crops treated and untreated with a biological product, were obtained (Fig. 2). A paler coloration corresponding to the control plot indicates a lower chlorophyll content in the wheat plants, and a brighter coloration of the area with the treated crops indicates a higher content of green pigments in the experimental plants. Such differences in the content of chlorophylls are associated with an increase in the photosynthetic productivity of the winter wheat under the influence of the plant protection products. 


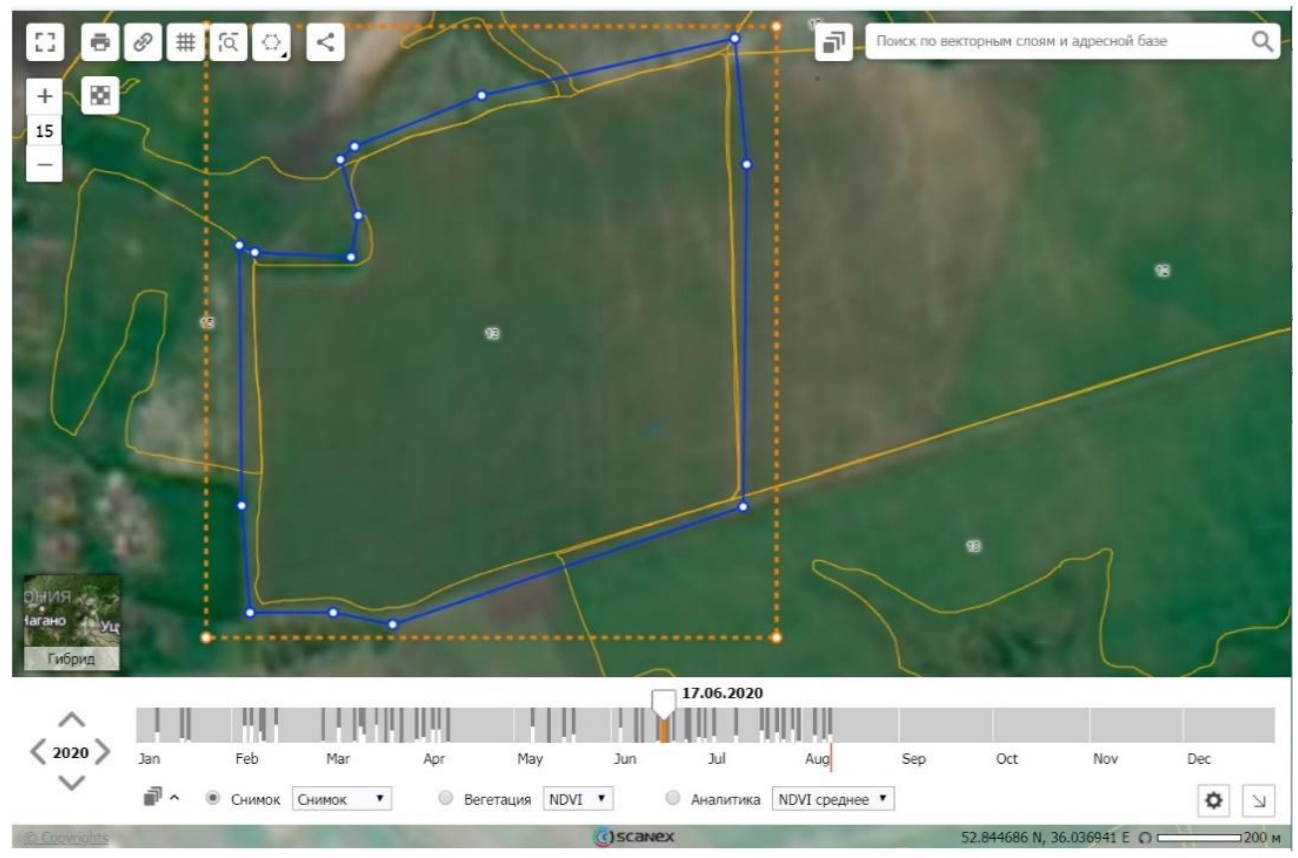

Fig. 2. The field with winter wheat at the early flowering phase.

It is known that using the NDVI to monitor the plant emergence in the fields, one can draw a conclusion that winter varieties of the cultivated plants are well overwintered [10].

For example, if at the beginning of the season the NDVI is below 0.15 , there is a high probability that all the plants on the plot have died. Typically, these values correspond to the plowed soil without vegetation. The NDVI value from 0.15 to 0.2 is also low. It may mean that the plants hibernated at an early phenological phase, before tillering. The NDVI value from 0.2 to 0.3 is a relatively good indicator, meaning that the plants had time to enter the tillering phase and resume vegetation. With some assumptions a NDVI value from 0.3 to 0.5 is a good indicator. The NDVI value exceeding 0.5 is an abnormal indicator after wintering.

As it can be seen from Figure 3, in our experience in March-April, the NDVI was rather low, it was only $0.05 \ldots 0.2$. This may indicate that the plants hibernated at an early phenological phase, before tillering. By May the vegetation index was slightly more than 0.25 , which was a relatively good indicator meaning that the plants had had time to enter the tillering phase and the renewal of vegetation.

In the middle of the season, the NDVI can be used to assess how the plants are developing in the field. In the experimental option, the vegetation index is close to 0.70 , which indicates a good development of the winter wheat.

At the end of the season, the NDVI can be used to determine the fields ready for harvest: the lower the index value, the closer to ripening this plot of the field. The optimal value of the index in this case is $0.3 \ldots 0.35$. In our experience, the NDVI is close to 0.3 by September, which indicates readiness for harvesting. 


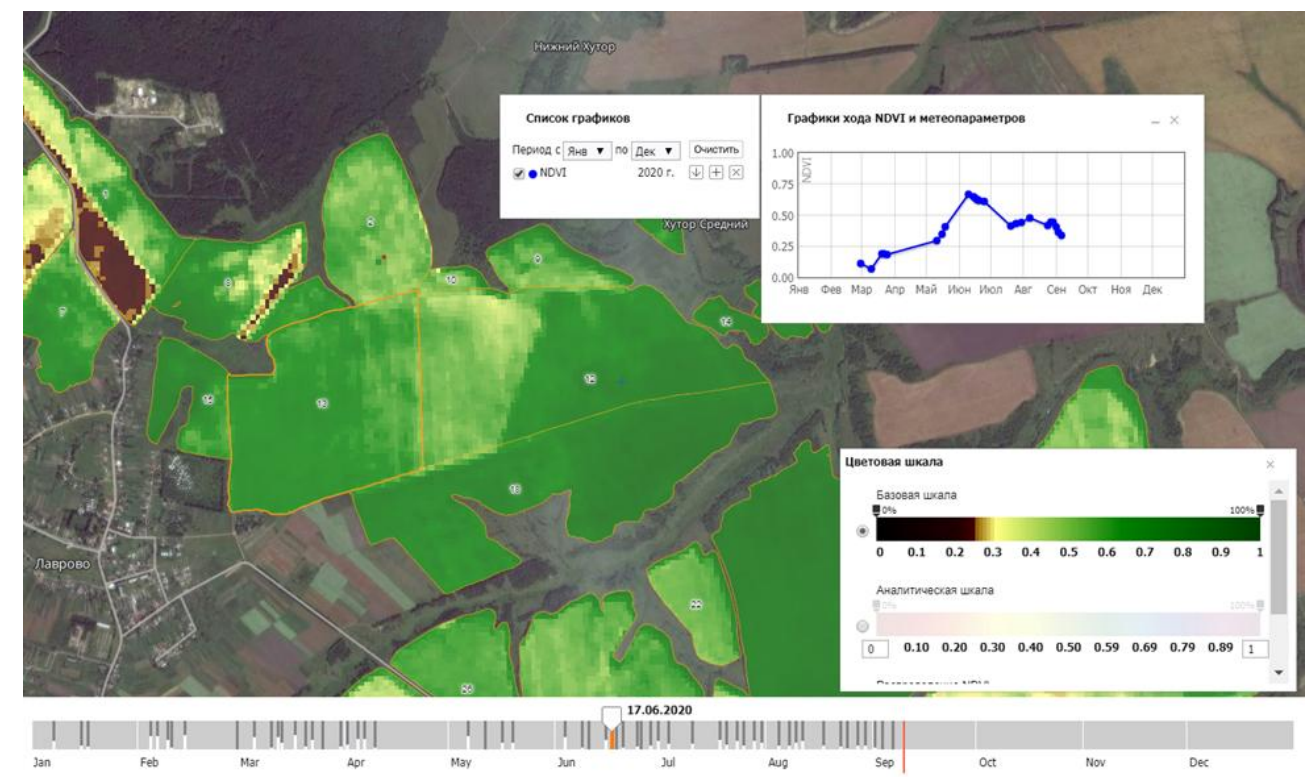

Fig. 3. Winter wheat field with color scale and NDVI.

On the control plot, which is well observed because of its pale coloring, the NDVI in the middle of the season was only $0.4 \ldots 0.45$. It predicts a lower yield compared to the plot treated with our biological product. The vegetation index on the experimental option in the middle of the season was $0.5 \ldots 0.85$, but it did not make up for the losses caused by the early wintering. In the current 2020 in the Russian Federation, the average yield was $30.6 \mathrm{c}$ / ha, and in the Orel region it was $45 \mathrm{c} /$ ha $[11,12]$. Thus, in the Orel region, the yield potential of the winter wheat is very high and it can be more than $45 \mathrm{c} /$ ha under the conditions of a favorable vegetation index associated with the leaving of plants for wintering.

Comparison of the NDVI with the final yield shows the validity of this statement, supported by the data obtained. On the control plot of the winter wheat "Moskovskaya 40", the obtained grain yield was $38.8 \mathrm{c} / \mathrm{ha}$, and on experimental one it was $41.5 \mathrm{c} /$ ha. The harvest from the experimental field outstrips the control option due to a greater density of planting, number of grains per spike, and a greater weight of 1000 grains.

The processing and analysis of the satellite images of the field with spring barley showed (Fig. 4) that the control plot had a very pale color, indicating a low content of green pigments in plants, which may cause a decrease in the barley yield. The treated with the biological product experimental plot has a slightly more intensive color associated with the accumulation of the green pigments increasing the photosynthetic potential. 


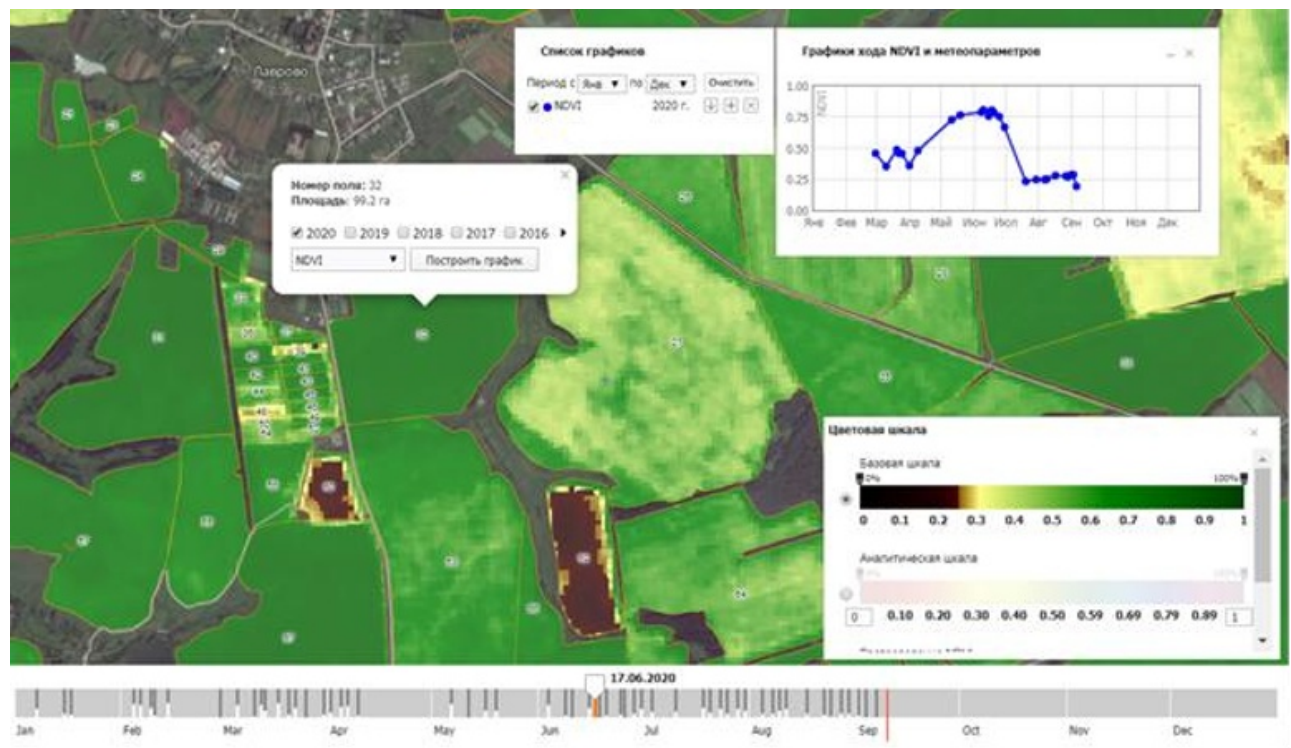

Fig. 4. Processed satellite images of the plots with the spring barley crops.

At the beginning of the vegetation in March-April, the NDVI on the experimental plot of the spring barley fluctuated strongly and averaged about 0.35 , and by the middle of the growing season it was 0.75 . The end of the growing season is characterized by the vegetation index of 0.25 , which indicates readiness for harvesting (Fig. 6). However, on the control plot the vegetation index indicators in the middle of the season were significantly lower and amounted to $0.35 \ldots 0.4$ according to the color scale. These NDVI values are very low, indicating unfavorable conditions for the development (for example, lack of moisture or nutrients).

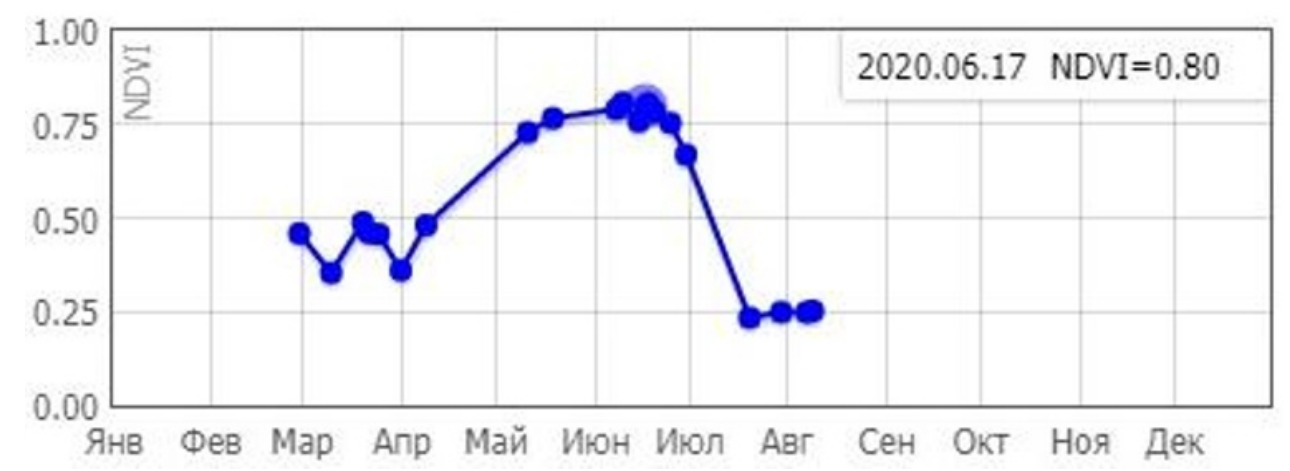

Fig. 5. The dynamics of changes in the NDVI indicator for the spring barley.

As a result of the research, it was determined that the spring barley yield on the control plot was $19.7 \mathrm{c} / \mathrm{ha}$, and on the experimental one it was $21.5 \mathrm{c} / \mathrm{ha}$, while the average spring barley yield in Russia was about $50 \mathrm{c} / \mathrm{ha}$. Thus, the assessment of the state of winter wheat and spring barley crops according to the average NDVI value, based on the satellite images, indicates a lack of nutrients or moisture on the plot, which is to be studied in further research. 


\section{Conclusions}

Thus, based on the research carried out, the following conclusions can be drawn:

- the assessment of the state of agricultural crops according to the average NDVI value, visual assessment of the distribution of the green matter according to the synthesized image, on the basis of the combination of the spectral channels according to the NDVI, based on satellite images and aerial mapping data, allows monitoring the development of plants and predicting yield throughout the entire period;

- the vegetation index NDVI of the winter wheat in spring, which is $0.05 \quad \ldots 0.2$, indicates that the plants have hibernated at an early phenological phase, before tillering, which can reduce the potential yield;

- high values of the NDVI equal to $0.75 \ldots 0.8$, indicate that the yield of the winter wheat can be more than $40 \mathrm{c} / \mathrm{ha}$;

- the values of the NDVI in the spring barley on the control plot are very low and amount to about 0.5 in the middle of the season, which predicts the yield to be twice lower than the optimal one. The treatment of plants with a biological product increased the yield by $9.1 \%$, but could not compensate the lack of nutrients.

The work was performed within the framework of a thematic task plan for the research work commissioned by the Ministry of Agriculture of Russia at the expense of the federal budget in 2020 (registration number R\&D AAAA-A20-120021190096-3, dated 11.02.2020).

\section{References}

1. V.J. Pooja, R.D. Ratnadeep, Priyanka Vegetation Indices for Crop Management. 6, 415 (2019)

2. V.J. Pooja, R.D. Ratnadeep, Hyperspectral Remote Sensing for Agriculture. 7, 172 (2017)

3. X. Jinru, S. Baofeng, Significant Remote Sensing Vegetation Indices, 1, 17 (2017)

4. J.O. Payero, C.M.U. Neale, J.L. Wright, Comparison of eleven vegetation indices for estimating plant height of alfalfa and grass, 20, 395 (2004)

5. P.S. Thenkabail, R.B. Smith, E.D. Pauw, Hyperspectral vegetation indices and their relationships with agricultural crop characteristics, 71, 182 (2000)

6. Patent of the RF No. 2463759. Means for the presowing treatment of the pea seeds / Pavlovskaya N.E., Gorkova I.V., Gagarina I.N., Borodin D.B., Borzenkova G.A. Patent for invention RUS 2463759 05/03/2011.

7. GOST 26205-91 Soils. Determination of the sliding compounds of phosphorus and potassium according to Machigin's method in the modification of the CSRIASA. Moscow: Committee for Standardization and Metrology of the USSR, 1992. - 8p.

8. GOST 26483-85 Soils. Preparation of salt extract and determination of its $\mathrm{pH}$ according to the method of the CSRIASA.-M .: USSR State Committee for Standards, 1985.- 4p.

9. GOST 26213-91 Soils. Methods for the determination of the organic matter. Moscow: Committee for Standardization and Metrology of the USSR, 1992.- 8p.

10. What is the NDVI index and how it makes a farmer's life easier [Electronic resource] access mode: https://blog.onesoil.ai/ru/what-is-ndvi (accessed data 20.10.2020)

11. Progress of the harvesting campaign 2020 in the Russian Federation by regions [Electronic resource] - access mode: http://zerno.ru/node/10943 (accessed data 03/20/2021)

12. M.A. Nikitina, I.A. Nikitin, N.G. Semenkina, I.V. Zavalishin, A.V. Goncharov, International Journal of Advanced Computer Science and Applications. 9 (5), 51-59 (2018) 